Supplement of Hydrol. Earth Syst. Sci., 21, 4347-4361, 2017

https://doi.org/10.5194/hess-21-4347-2017-supplement

(C) Author(s) 2017. This work is distributed under

the Creative Commons Attribution 3.0 License.

(c) (1)

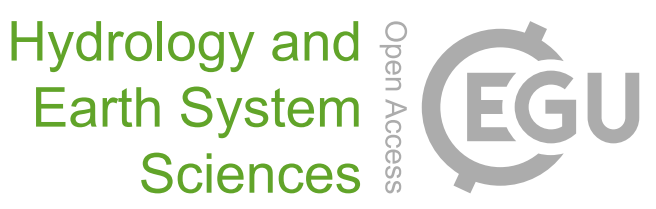

Supplement of

\title{
An assessment of the performance of global rainfall estimates without ground-based observations
}

\section{Christian Massari et al.}

Correspondence to: Christian Massari (christian.massari@irpi.cnr.it)

The copyright of individual parts of the supplement might differ from the CC BY 3.0 License. 


\section{ADDITIONAL FIGURES}

The supporting information contains 2 additional figures to complement the results shown in the paper (Figures S1 and S2). In particular, the figures show the same results shown in the main text of the manuscript but with the assumption of multiplicative error model (i.e., by using log-transformed precipitation). The description of the figures is given in the main text of the 5 manuscript. 


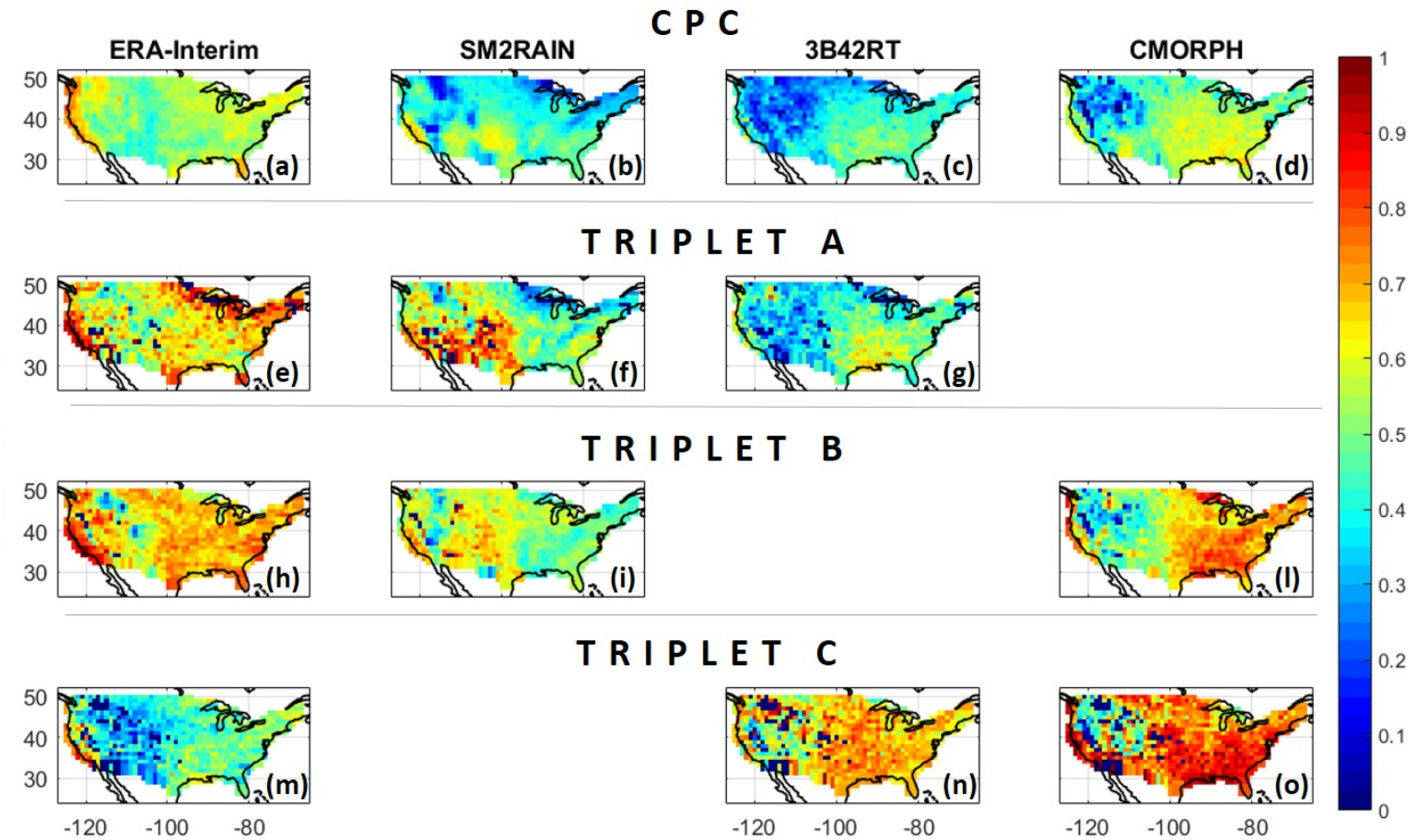

Lo n g i t u d e

Figure S1. CPC-based (a, b , c and d) and TC-based (e-o) correlation coefficient obtained for the triplets: i) ERA-Interim-SM2RAIN-3B42RT (Triplet A: e, f, g), ii) ERA-Interim-SM2RAIN-CMORPH (Triplet B: h, i, l) and iii) ERA-Interim-3B42RT-CMORPH (Triplet C: m, n, o) during the period 2012-2015 using a multiplicative error model. 


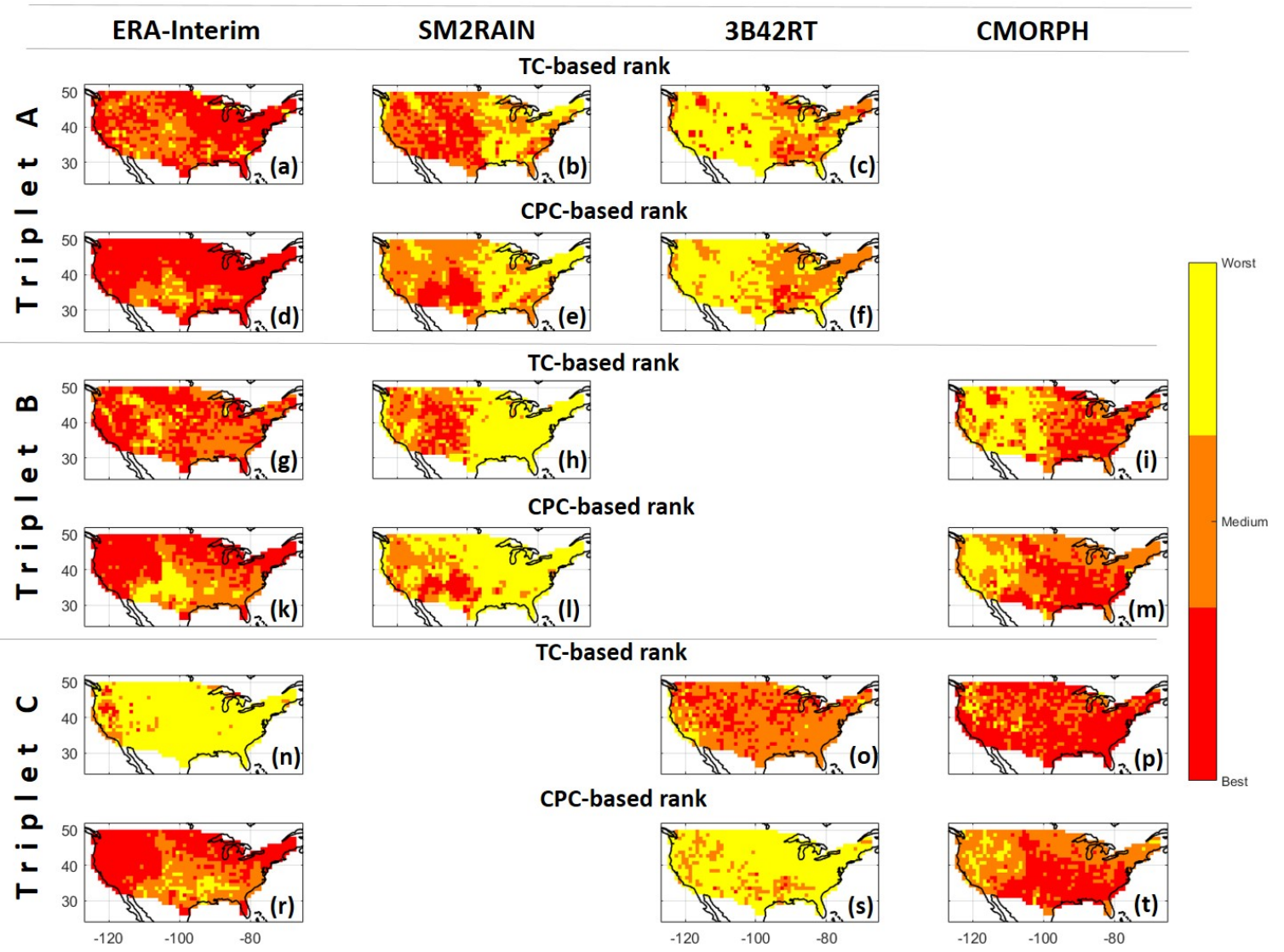

Lo n g i t u d e

Figure S2. Rank based on CPC-based correlation (CPC-based rank in the figure) and TC-based correlation (TC-based rank in the figure) of the triplets: i) ERA-Interim-SM2RAIN-3B42RT (Triplet A: a, b, c for TC-based rank and d, e, f for CPC-based rank), ii) ERA-InterimSM2RAIN-CMORPH (Triplet B: g, h, i for TC-based rank and k, 1, $\mathrm{m}$ for CPC-based rank) and iii) ERA-Interim-3B42RT-CMORPH (Triplet C: $\mathrm{n}, \mathrm{o}, \mathrm{p}$ for TC-based rank and r, s, $\mathrm{t}$ for CPC-based rank) during the period 2012-2015 using a multiplicative error model. 